\title{
Synthesis of 4-Phenylphthalonitrile by Vapor-Phase Catalytic Ammoxidation of Intermediate 4-Phenyl-o-Tolunitrile: Reaction Kinetics
}

\author{
G. A. Bagirzade ${ }^{1}$, D. B. Tagiyev², M. R. Manafov ${ }^{1}$ \\ ${ }^{1}$ Institute of Chemical Problems Named after Academician M. F. Nagiyev, National Academy of Sciences of Azerbaijan, \\ Baku, Azerbaijan \\ ${ }^{2}$ Azerbaijan Medical University, Baku, Azerbaijan \\ Email: mmanafov@gmail.com
}

Received November 11, 2013; revised December 11, 2013; accepted December 18, 2013

Copyright (c) 2014 G. A. Bagirzade et al. This is an open access article distributed under the Creative Commons Attribution License, which permits unrestricted use, distribution, and reproduction in any medium, provided the original work is properly cited. In accordance of the Creative Commons Attribution License all Copyrights (C) 2014 are reserved for SCIRP and the owner of the intellectual property G. A. Bagirzade et al. All Copyright (C) 2014 are guarded by law and by SCIRP as a guardian.

\begin{abstract}
Kinetic regularities of 4-phenyl-o-tolunitrile ammoxidation on $\mathrm{V}$-Sb-Bi- $\mathrm{Zr} / \gamma-\mathrm{Al}_{2} \mathrm{O}_{3}$ oxide catalyst in the temperature interval 633 - $673 \mathrm{~K}$ have been studied. It has been established that rates of conversion of 4-phenyl-o-tolunitrile into the aimed 4-phenylphthalonitrile and $\mathrm{CO}_{2}$ are described by half-order equation on concentration of substratum and to be independent of the oxygen and ammonia partial pressures. It has been revealed that formation of 4-phenylphthalimide from byproducts is due to hydrolysis of 4-phenylphthalonitrile; carbon dioxide is produced by oxidation of 4-phenyl-o-tolunitrile and decarboxylation of 4-phenylphthalimide, and 4-phenylbenzonitrile is produced from 4-phenyl-o-tolunitrile and 4-phenylphthalimide.
\end{abstract}

\section{KEYWORDS}

\section{Catalytic Ammoxidation; Partial Pressures; 4-Phenylphthalimide; Vapor-Phase; Electron-Donorship; Kinetic} Measurements

\section{Introduction}

The vapor-phase catalytic ammoxidation of 4-phenyl-oxylene can give with a yield of $80 \%$ 4-phenylpthalonitrile, a feedstock for the synthesis of copper tetraphenyltetrazoporphinate (copper tetraphenyl phthalocyanine), which in turn is used for manufacturing phthalocyanine pigments and turquoise and yellow hue dyes [1]. The use of 4-phenylpthalonitrile will make it possible to replace highly chlorinated copper phthalocyanine, which is manufactured through quite a sophisticated, environmentally unfriendly process of chlorination of copper phthalocyanine in an aluminum chloride-sodium chloride melt [2]. With this purpose, we use expediently $\mathrm{V}-\mathrm{Sb}-\mathrm{Bi}-\mathrm{Zr} / \gamma-\mathrm{Al}_{2} \mathrm{O}_{3}$-oxide catalyst for preparation of 4-phenylphthalonitrile in the vapour-phase ammoxidation of 4-phenyl-o-xylene [1,3]. Studying the kinetic regularities of this reaction in contribution [4] is shown that 4-phenyl-o-tolunitrile is an intermediate at formation of the aimed 4-phenylphthalo-nitrile.
Indeed, in 4-phenyl-o-xylene molecule, due to electronic factor of phenyl group, para-methyl group is activated first, and as a result, an appropriate intermediate mononitrile is formed initially, which, in turn, is converted to the aimed dinitrile. Upon introducing phenyl group into 4-position of $o$-xylene aromatic ring conjugation, it does not play an appriciable role as the resonance constants of phenyl and methyl groups, located in parapositions, are distinguished insignificantly [5]. So long as phenyl group is related to substituents of III kind [6], which may show both electron-donor and electron-acceptor properties and, taking into account the absence of an appriciable role of conjugation, i.e. electron-donorship of phenyl group, then it is possible to make a conclusion that phenyl group in the 4-phenyl-o-xylene molecule shows the electron-acceptor property. Consequently, in 4-phenyl-o-xylene molecule on the basis of electronacceptor property of phenyl group and, only positive inductive (+I) effect of para-methyl group, it is possible to 
assert that both are directed to a side of activation of para-methyl group relative to phenyl substituents [7]. Here it should be noted that in 4-phenyl-o-xylene molecule phenyl group, it is known [8], to not influence on activation of meta-methyl group, which itself shows only $+\mathrm{I}$ effect. Regarding the mononitrile formation as an intermediate product, it is important to note that at studying kinetic regularities of ammoxidation of 4-brom-o-xylene on the $\mathrm{V}-\mathrm{Sb}-\mathrm{Bi}-\mathrm{Zr} / \gamma-\mathrm{Al}_{2} \mathrm{O}_{3}$-oxide catalyst, 4-brom-o-tolunitrile is the intermediate product at preparation of the aimed 4-bromphthalonitrile $[9,10]$.

The objective of this work was to study kinetic regularities of 4-phenyl-o-tolunitrile conversion in the ammoxidation reaction on the indicated catalyst.

\section{Methods and Apparatus}

Kinetic measurements of 4-phenyl-o-tolunitrile conversion and chromatographic separation of catalyzate components, and a quantitative calculation of their content were carried out in accordance with the earlier developed methods [4]. Kinetic measurements were performed in a setup with a vibrating fluidized-bed, gradientless flow reactor of $20-\mathrm{cm}^{3}$ capacity made from $12 \mathrm{Kh} 18 \mathrm{~N} 10 \mathrm{~T}$ steel. The products absorbed by 1,4-dioxane were determined on a Chrome-5 chromatograph equipped with an FID and a column of $1.2 \mathrm{~m}$ length. The column packing was Chromaton N-AW (0.2 - $0.25 \mathrm{~mm}$ ) coated with a mixed stationary phase of Apiezon L (21\%) and PEG 40000 (0.5\%) or with Polisorb-1 (0.25 - $0.5 \mathrm{~mm})$ alone. Carbon dioxide was determined on an LKhM-8MD chromatograph with triethylene glycol butyrate supported on INZ600 (calcined diatomaceous earth) as the stationary phase. Separation of $\mathrm{O}_{2}$ and $\mathrm{N}_{2}$ was carried out on the same chromatoraph using a parallel column packed with $\mathrm{NaX}$.

\section{Experimental}

In the products of the reaction of ammoxidation of 4phenyl-o-tolunitrile (I) on the $\mathrm{V}-\mathrm{Sb}-\mathrm{Bi}-\mathrm{Zr} / \gamma-\mathrm{Al}_{2} \mathrm{O}_{3}$-oxide catalyst 4-phenylphthalonitrile (II), 4-phenylpthalimide (III), 4-phenylbenzonitrile (IV), carbon dioxide, unreacted I, oxygen and the diluent gas nitrogen were determined by gas chromatography. The reaction gases were successively passed through a 1.4-dioxane-filled trap for absorption of nitriles, and III and a sulfuric acid-filled trap for absorption of ammonia. The concentration of ammonia at the reactor outlet was determined, by titration of unreacted sulfuric acid from the second trap.

\section{Results and Discussion}

Influence of partial pressures of oxygen $P_{\mathrm{O}_{2}}$ and ammonia $P_{\mathrm{NH}_{3}}$ at values $P_{\mathrm{NH}_{3}}$, more than a certain value, noted as $\left(P_{\mathrm{NH}_{3}}\right)_{\min }$ [4], and also contact time $\tau$ on the process rate in the temperature range of 633 - $673 \mathrm{~K}$ were studied for ascertainment of kinetic dependence character of ammoxidation reaction of 4-phenyl-o-tolunitrile.

Influence of oxygen concentrations on the indicators of ammoxidation process of 4-phenyl-o-tolunitrile was carried at initial partial pressures $P_{1}^{0} 1.30 \mathrm{kPa}$ and $P_{\mathrm{NH}_{3}}^{0} 32.49 \mathrm{KPa}$. In the studied range of $P_{\mathrm{O}_{2}}$ (1.83 $18.70 \mathrm{KPa}$ ), the rate of summary conversion of 4-phenyl$o$-tolunitrile $\left(W_{\mathrm{I}}\right)$, and also rates of 4-phenylphthalonitrile and $\mathrm{CO}_{2}$ formation do not depend on partial pressures of oxygen at $\tau 0.27 \mathrm{~s}$ in temperatures 653 and $673 \mathrm{~K}$.

Study of $P_{\mathrm{NH}_{3}}$ influence at $\tau 0.27 \mathrm{~s}, P_{\mathrm{I}}^{0} 1.30 \mathrm{kPa}$ and $P_{\mathrm{O}_{2}}^{0} \quad 8.19 \mathrm{kPa}$, in temperatures 653 and $673 \mathrm{~K}$ on $W_{I}$ and rates of partial reactions was shown that the rate of 4-phenyl-o-tolunitrile gross-conversion, and also rates of 4-phenylphthalonitrile and $\mathrm{CO}_{2}$ formation do not depend on ammonia concentration in range $18.83-57.81 \mathrm{kPa}$.

Tests results on $\tau$ variation at $P_{\mathrm{I}}^{0} 1.52 \mathrm{kPa}, P_{\mathrm{O}_{2}}^{0}$ $9.55 \mathrm{kPa}$ and $P_{\mathrm{NH}_{3}}^{0} 53.03 \mathrm{kPa}$ are presented in Table 1 . As seen, an increase of $\tau$ leads to growth of 4-phenyl-otolunitrile conversion degree $(\alpha)$ and decrease of $W_{\mathrm{I}}$. Upon increasing $\tau$ selectivity of 4-phenyl-o-tolunitrile conversion to 4-phenylphthalonitrile decreases but selectivity of 4-phenylphthalimide and 4-phenylbenzonitrile formation increases. The dependence of selectivity of $\mathrm{CO}_{2}$ formation on $\tau$ is expressed weaker. This implies that $\mathrm{CO}_{2}$ as opposed to 4-phenylphthalimide and 4-phenylbenzonitrile, generally, is formed immediately from 4-phenyl-o-tolunitrile. Formation of 4-phenylphthalimide and 4-phenylbenzonitrile occurs by a consecutive route. The absence of 4-phenylphthalimide and 4-phenylbenzonitrile in the reaction products at short time of contact and preparation of 4-phenyl-o-tolunitrile at relatively high conversion indicates to the consecutive character of their formation, as well. Thus, an analysis of changing of formation selectivity of the reaction products $\left(S_{i}\right)$ in dependence on $\alpha$ gives a possibility to assume that 4-phenylphthalonitrile is subjected to the secondary conversions in the ammoxidation reaction of 4-phenyl-o-tolunitrile under an action of $\mathrm{H}_{2} \mathrm{O}$, being a product of concomitant reactions [3,11] of ammoxidation-oxidative dehydrogenation and deep substratum oxidation. In compliance with above-mentioned data 4-phenylphthalo-nitrile, appears, to hydrolyse to 4-phenylphthalimide, which in turn is decarboxylated to 4-phenylbenzonitrile. Furthermore, apparently, the additional route of 4-phenylbenzonitrile formation exists by oxidative destruction immediately from 4-phenyl-o-tolunitrile, that it is shown more clearly with increasing temperature and contact time. This result is conformed to data [4] at studying kinetics of 4-phenyl-o-xylene ammoxidation, because of in the latter case 4-phenyl-o-tolunitrile is produced as an intermediate product and subjected to the further conversion.

On the basis of carried out investigations a scheme of reaction flowing of 4-phenyl-o-tolunitrile ammoxidation can be presented as: 


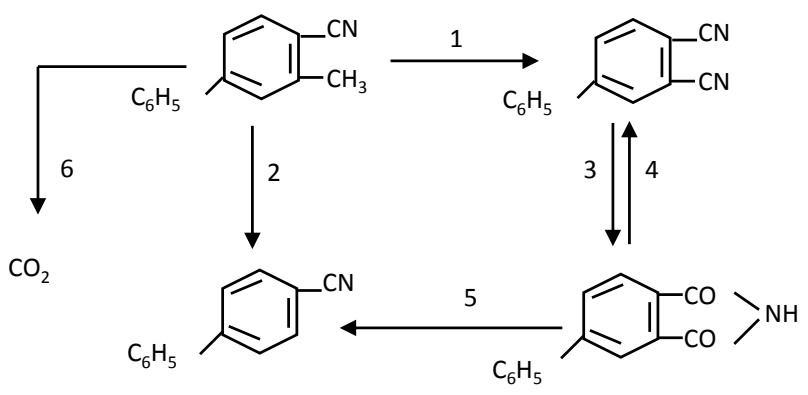

Therefore, kinetics of 4-phenyl-o-tolunitrile summary conversion is described by Equation (1):

$$
W_{1}=k P_{1}^{n}
$$

where $k$-apparent constant of the rate of summary conversion of the substratum (I).

Experimental data processing in the coordinates $\lg W_{\mathrm{I}}=k P_{\mathrm{I}}$ (Figure 1) at $673 \mathrm{~K}$ shows that reaction order, describing by Equation (1) is equal to 0.5 . The analogous dependences were observed at 633 and $653 \mathrm{~K}$. Taking into account aforesaid, Equation (1) is written as:

$$
W_{1}=k P_{1}^{0.5}
$$

Consistency of constant values at changing of contact time testifies about Equation implementation (2).

Apparent activation energy of 4-phenyl-o-tolunitrile conversion reaction, determined graphically from Arrhenius curve is found $116.53 \mathrm{~kJ} / \mathrm{mole}$ (Figure 2). Therefore, a numerical value of the constant of 4-phenyl-o-tolunitrile conversion rate is expressed by the Equation (3):

$$
k=k_{0} \exp (116530 / R T)
$$

Taking into account above stated, the rates on separate routes in the range of oxygen and ammonia partial pressures, is higher their minimal values, may be described by the following Equations (4)-(9), that is conformed with data [4].

$$
\begin{gathered}
W_{1}=k_{1} P_{1}^{0.5} \\
W_{2}=k_{2} P_{1} \\
W_{3}=k_{3}\left(P_{\mathrm{II}} P_{\mathrm{H}_{2} \mathrm{O}} / P_{\mathrm{NH}_{3}}\right) \\
W_{4}=k_{4}\left(P_{\mathrm{III}} / P_{\mathrm{H}_{2} \mathrm{O}}\right) \\
W_{5}=k_{5} \\
W_{6}=k_{6} P_{1}^{0.5}
\end{gathered}
$$

Constants of Equations (4)-(9) were selected at condition of minimization of squares sum of relative errors between experimental and calculated buildup rates of all reaction products.

$$
k_{1}=10^{9.48} \exp (-118047.4 / R T)
$$

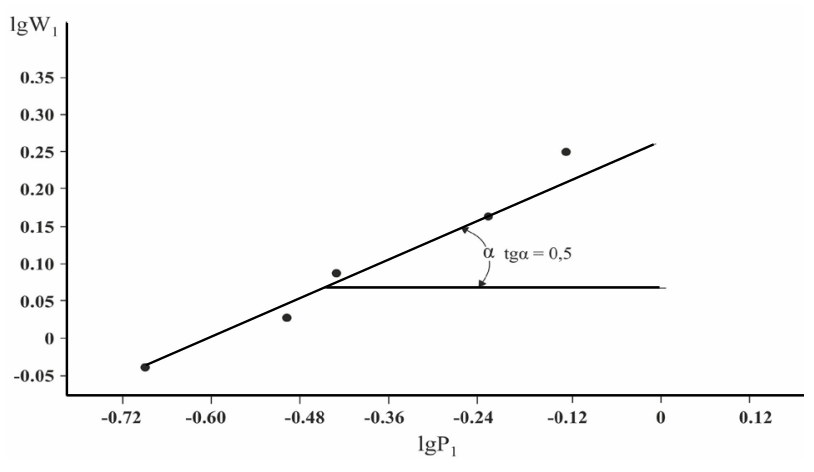

Figure 1. Dependence of $\lg W_{\mathrm{I}}$ on $\lg P_{\mathrm{I}}$ in the ammoxidation reaction of 4-phenyl-o-tolunitrile at $T=673 \mathrm{~K}$.

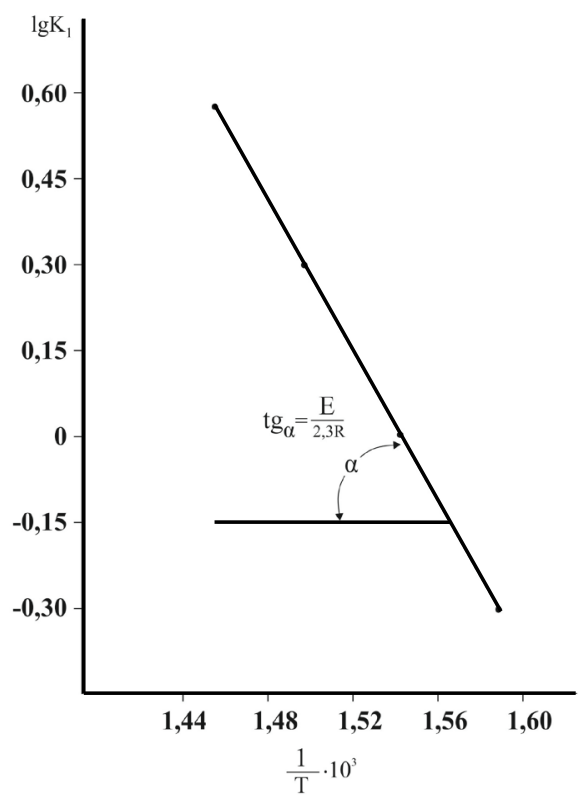

Figure 2. Dependence of logarithm of 4-phenyl-o-tolunitrile gross-conversion constant on reverse temperature.

$$
\begin{gathered}
k_{2}=10^{9.95} \exp (-148560.9 / R T) \\
k_{3}=10^{-12.51} \exp (154970.3 / R T) \\
k_{4}=10^{-3.90} \exp (51394.2 / R T) \\
k_{5}=10^{5.29} \exp (-91939.5 / R T) \\
k_{6}=10^{11.39} \exp (-162127.5 / R T)
\end{gathered}
$$

Activation energy is given in $\mathrm{J} / \mathrm{mole}$.

Table 2 presents the values for the product buildup rates and the 4-phenyl-o-tolunitrile consumption rate calculated by Equations (4)-(9) with the use of the constants found for these equations. The difference between experimental and calculated values does not exceed the experiment accuracy. It is also seen from Table 2 that at 653 $\mathrm{K}$ analogous regularities are observed as at 633 and 673 $\mathrm{K}$ in dependence on $\tau$ (Table 1 ). 
Table 1. Influence of contact time on kinetics of 4-phenyl-o-tolunitrile ammoxidation.

(a)

\begin{tabular}{|c|c|c|c|c|c|c|}
\hline \multirow{2}{*}{$\tau, \mathrm{s}$} & \multirow{2}{*}{$\alpha, \%$} & \multirow{2}{*}{$W_{\mathrm{tot}}, \mathrm{mmol} / \mathrm{g} \cdot \mathrm{h}$} & \multicolumn{4}{|c|}{$S_{i}, \%$} \\
\hline & & & II & III & IV & $\mathrm{CO}_{2}$ \\
\hline \multicolumn{7}{|c|}{$633 \mathrm{~K}$} \\
\hline 0.14 & 9.23 & 0.65 & 98.22 & - & - & 1.78 \\
\hline 0.27 & 16.67 & 0.60 & 98.21 & - & - & 1.79 \\
\hline 0.43 & 25.34 & 0.57 & 96.93 & 1.26 & - & 1.81 \\
\hline 0.59 & 32.67 & 0.54 & 94.89 & 1.61 & 1.67 & 1.83 \\
\hline 0.75 & 39.73 & 0.51 & 93.85 & 2.60 & 1.71 & 1.84 \\
\hline 0.91 & 45.50 & 0.48 & 92.81 & 3.47 & 1.86 & 1.86 \\
\hline \multicolumn{7}{|c|}{$673 \mathrm{~K}$} \\
\hline 0.14 & 30.53 & 2.15 & 97.11 & - & - & 2.89 \\
\hline 0.27 & 50.60 & 1.82 & 97.10 & - & - & 2.90 \\
\hline 0.43 & 66.35 & 1.49 & 97.09 & - & - & 2.91 \\
\hline 0.59 & 76.46 & 1.26 & 94.58 & 0.67 & 1.83 & 2.92 \\
\hline 0.75 & 82.23 & 1.07 & 93.87 & 1.01 & 2.19 & 2.94 \\
\hline 0.91 & 87.18 & 0.93 & 93.49 & 1.31 & 2.25 & 2.95 \\
\hline
\end{tabular}

(b)

\begin{tabular}{|c|c|c|c|c|c|c|c|}
\hline \multirow{2}{*}{$\tau, \mathrm{s}$} & \multirow{2}{*}{$\alpha, \%$} & \multirow{2}{*}{$W_{\text {tot }}, \mathrm{mmol} / \mathrm{g} \cdot \mathrm{h}$} & \multicolumn{5}{|c|}{$P_{i}, \mathrm{kPa}$} \\
\hline & & & I & II & III & $\mathrm{NH}_{3}$ & $\mathrm{H}_{2} \mathrm{O}$ \\
\hline \multicolumn{8}{|c|}{$633 \mathrm{~K}$} \\
\hline 0.14 & 9.23 & 0.65 & 1.375 & 0.14 & - & 52.89 & 0.43 \\
\hline 0.27 & 16.67 & 0.60 & 1.263 & 0.25 & - & 52.78 & 0.77 \\
\hline 0.43 & 25.34 & 0.57 & 1.131 & 0.37 & 0.0048 & 52.66 & 1.16 \\
\hline 0.59 & 32.67 & 0.54 & 1.020 & 0.47 & 0.0080 & 52.56 & 1.48 \\
\hline 0.75 & 39.73 & 0.51 & 0.913 & 0.56 & 0.0157 & 52.47 & 1.78 \\
\hline 0.91 & 45.50 & 0.48 & 0.826 & 0.64 & 0.0239 & 52.39 & 2.03 \\
\hline \multicolumn{8}{|c|}{$673 \mathrm{~K}$} \\
\hline 0.14 & 30.53 & 2.15 & 1.053 & 0.45 & - & 52.58 & 1.42 \\
\hline 0.27 & 50.60 & 1.82 & 0.748 & 0.74 & - & 52.29 & 2.36 \\
\hline 0.43 & 66.35 & 1.49 & 0.510 & 0.98 & - & 52.05 & 3.09 \\
\hline 0.59 & 76.46 & 1.26 & 0.357 & 1.10 & 0.0080 & 51.93 & 3.50 \\
\hline 0.75 & 82.23 & 1.07 & 0.269 & 1.17 & 0.0130 & 51.86 & 3.75 \\
\hline 0.91 & 87.18 & 0.93 & 0.194 & 1.23 & 0.0170 & 51.80 & 3.97 \\
\hline
\end{tabular}


Table 2. Dependence of buildup rates of reaction products and 4-phenyl-o-tolunitrile conversion on contact time (653 K, $P_{\mathrm{I}}^{0}$ $\left.1.52 \mathrm{kPa}, P_{\mathrm{O}_{2}}^{0} 9.55 \mathrm{kPa}, P_{\mathrm{NH}_{3}}^{0} 53.03 \mathrm{kPa}\right)$.

(a)

\begin{tabular}{|c|c|c|c|c|c|}
\hline \multirow{2}{*}{$\tau, \mathrm{s}$} & \multicolumn{5}{|c|}{$P_{i}, \mathrm{kPa}$} \\
\hline & I & II & III & $\mathrm{NH}_{3}$ & $\mathrm{H}_{2} \mathrm{O}$ \\
\hline 0.14 & 1.249 & 0.26 & - & 52.77 & 0.81 \\
\hline 0.27 & 1.031 & 0.47 & - & 52.56 & 1.48 \\
\hline 0.43 & 0.828 & 0.66 & 0.009 & 52.37 & 2.08 \\
\hline 0.59 & 0.672 & 0.80 & 0.013 & 52.23 & 2.52 \\
\hline 0.75 & 0.557 & 0.90 & 0.021 & 52.13 & 2.86 \\
\hline 0.91 & 0.449 & 0.99 & 0.031 & 52.04 & 3.16 \\
\hline
\end{tabular}

(b)

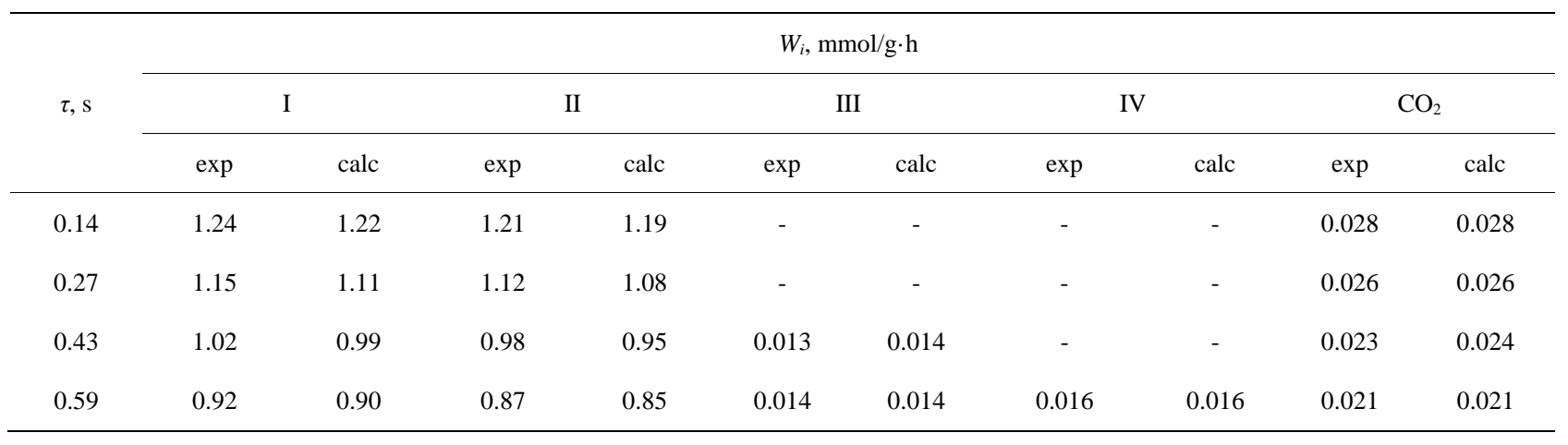

\section{Conclusions}

1) Kinetic regularities of I ammoxidation on V-Sb-Bi$\mathrm{Zr} / \gamma-\mathrm{Al}_{2} \mathrm{O}_{3}$ oxide catalyst in the temperature interval 633 - $673 \mathrm{~K}$ have been studied.

2) Rates of conversion of substratum into the aimed II and $\mathrm{CO}_{2}$ are described by half-order equation on concentration of I and to be independent of the oxygen and ammonia partial pressures.

3) It has been revealed that formation of III occurs due to hydrolysis of II; carbon dioxide is produced by oxidation of I and decarboxylation of III, and IV is produced from I and III.

\section{REFERENCES}

[1] G. A. Bagirzade, "Innovative Chemical Technologies and Biotechnologies of Materials and Products," Abstracts of Papers of II International Conference of the Mendeleev Russian Chemical Society, RKhTU im. D. I. Mendeleeva, Moscow City, 2010, p. 197. (in Russian)

[2] R. G. Rizaev, V. E. Sheinin, G. A. Bagirzade and M. M. Mirataev, "Abstracts of Papers of the First Baku International Conference on Petroleum Chemistry,” Baku, 1994, p. 34. (in Russian)
[3] G. A. Bagirzade, "Resource-Saving and Power-Efficient Technologies in Chemical and Petrochemical Industries," In: Abstracts of Papers of III International Conference of the Mendeleev Russian Chemical Society (RKhTU im. D. I. Mendeleeva, Moscow, 2011), p. 133. (in Russian)

[4] G. A. Bagirzade, "Preparation of 4-Phenylphthalonitrile by Vapor-Phase Ammoxidation of 4-Phenyl-o-Xylene: Reaction Kinetics,” Neftekhimiya, Vol. 52, No. 2, 2012, pp. 105-112.

[5] G. A. Bagirzade, “On the Reactivity of O-Xylene and It 4Substituted at the Heterogeneous Catalytis Oxidative Ammonolysis,” Izvestia Vysshykh Uchebnykh Zavedeniy Khimia I Khimicheskay Tekhnologia, Vol. 52, No. 12, 2009, pp. 47-49.

[6] V. V. Plemenkov, "Electronic and Steric Structure of Monofunctional Cyclopropanes," Russian Journal of Organic Chemistry, Vol. 33, No. 6, 1997, pp. 849-859.

[7] G. A. Bagirzade, "On Sequence of Activation of Methyl Groups of 4-Phenyl- and 4-Brom-o-Xylenes at the Heterogeneous Catalytic Oxidative Ammonolysis,” Izvestia Vysshykh Uchebnykh Zavedeniy Khimia I Khimicheskay Tekhnologia, Vol. 55, No. 5, 2012, pp. 23-27.

[8] A. A. Ravdel and A. M. Ponomarevf, "Short Handbook of Chemical-Physical Parameters,” Khimiya, Leningrad, 1983. (in Russian)

[9] G. A. Bagirzade, "Kinetics of Oxidative Ammonolysis of 
4-Brom-o-Xylene I. Transformation of 4-Brom-o-Xylene and 4-Brom-o-Tolunitrile,” Russian Journal of General Chemistry, Vol. 80, No. 8, 2010, pp. 1360-1364.

[10] G. A. Bagirzade, "Kinetics of Oxidative Ammonolysis of 4-Brom-o-Xylene II. Formation of By-Products,” Russian Journal of General Chemistry, Vol. 80, No. 9, 2010, pp.
1460-1466.

[11] G. A. Bagirzade, V. Y. Sheinin, Z. Y. Magerramova and R. G. Rizaev, "Towards the Issue on Separation of Crystalline Mixture of the Main Products of Vapor Phase Ammoxidation of O-Xylene and Ist 4-Substitutives," Azerbaijan Chemical Journal, Vol. 1, 2000, pp. 60-63. 